\title{
Role of Herbal Formulations in the Treatment of Helmintheasis
}

\author{
Amit Sharma *, Sachin Kumar Singh, Monika Golati \\ School of pharmaceutical science, Lovely professional University, Punjab India
}

Address for Correspondence: Amit Sharma; Amit.pharma69@gmail.com

Received:
01.03.2019
Accepted:
25.03.2019
Keywords
Herbal Drugs;
Natural
Medicines;
Parasites.

Received:

Accepted:

Keywords

Herbal Drugs;

Natural

Parasites.

\begin{abstract}
Helminthiasis is a macro parasitic disease of humans in which a part of body gets infected with the parasitic worms such as pinworm, roundworm or tapeworm. Intestinal parasitic helminths such as roundworms (Ascaris lumbricoides), hookworms (Ancylostoma doudenale and Necator americanus) and whipworm (Trichuris trichiura) are commonly found in human gut. Parasitic infections transmitted through different sources (water, soil, food and vegetables) can induce other complications such as gastrointestinal disorders, malnutrition, anemia and allergies and sometimes may lead to life threatening complications. Anthelmintics are drugs that act either locally to expel worms from gastrointestinal tract or systematically to eradicate adult helminths. Number of synthetic drugs used to control and prevent the infestation related to worms include mebendazole, albendazole, piperazine and pyrantel. These drugs are known to have adverse effects like tolerance, resistance, nausea, vomiting, drowsiness, dizziness, and abdominal pain on long term use. It has been well evidenced that the traditional herbal medicine hold a great promise as a source of easily available, effective and cost effective anthelmintic agents. Herbal medicines are used in Ayurveda, Naturopathy and Homeopathy, traditional and Native American medicines. Many herbs are used as natural anthelmintics included Embelia ribes (vidang), Mallotus phillipensis (Kampillak), Thespesia lampus (Ranibhendi), Chloroxylon swietenia (yellow wood), Carissa spinarum (karaunda), Baliospermum montanum (Danti), Centratherum anthelminticum (Kalijiri),Trigonella foenum-graecum (fenugreek,methi), Coriandrum sativum (coriander), Azadirachta indica (neem), Caesalpinia crista, Cassia tora (sickle senna) etc. The drugs exhibit various mode of action again helmenthic infestation. These include irrevecible inhibition of glucose uptake, inhibition of fumarate reductase stimulation of ganglia to produce spastic muscle paralysis, flaccid paralysis of worm muscle, inhibition of filarial cholinesterases. Some formulations are also available in market. These include, Krimikuthar Rasa, Krimimudgar Rasa,Krimihar Syrup, Vidangarishta etc. In the present study, different herbal drugs and formulations that are used to treat helminthiasis are discussed. (C) 2019 iGlobal Research and Publishing Foundation. All rights reserved.
\end{abstract}

Cite this article as: Sharma, A.; Singh, S.K.; Golati, M. Role of Herbal Formulations in the Treatment of Helmintheasis. Indo Global J. Pharm. Sci., 2019; 9(2Suppl.): $124 . \quad$ DOI: http://doi.org/10.35652/IGJPS.2019.92S22 .

Indo Global Journal of Pharmaceutical Sciences( ISSN 2249 1023; CODEN- IGJPAI; NLM ID: 101610675) indexed and abstracted in CrossRef (DOI Enabling), UGC CARE Journal List, EMBASE(Elsevier), National Library of Medicine (NLM) Catalog, ResearchGate, Publons, CAS (ACS), Index Copernicus, Google Scholar and many more. For further details, visit http://iglobaljournal.com

This is a special issue as an outcome of 'RAPSCON-2019' sponsored by APTI and organized by Sri Sai College of Pharmacy, Manawala, Amritsar, Punjab, India. Relaxation offered in journal format. 